\title{
Visualising the Doctoral Research Process: An Exploration into Empirical Research Processes of Emerging Researchers
}

\author{
Kwong Nui Sim \\ Victoria University of Wellington \\ Wellington, New Zealand \\ Russell Butson \\ University of Otago \\ Dunedin, New Zealand
}

\begin{abstract}
The completion of a doctoral programme requires a fundamental knowledge of the research process. It is assumed and expected by academic staff that $\mathrm{PhD}$ students are aware of the research process prior to undertaking doctoral research. This study addresses the degree to which these assumptions are valid, by investigating doctoral students' understanding and practices of doctoral research. Nine doctoral students, at various phases of their dissertation and from different discipline backgrounds, were asked to illustrate, through diagrams, the processes involved in their doctoral research. They were invited to discuss their illustrated ideas and explain in more detail the processes and practices they employed, including the role of technology. The findings revealed a variety of processes characterised as: a) Linear vs. Non-linear; b) Traditional vs. Non-traditional; c) Simple vs. Complicated. In addition, the students exhibited diverse styles of presenting the research process through: 1) the way they started their research; 2) the language they used to describe the process; and 3) the linearity and complexity of their doctoral research. The paper concludes with a number of important insights with regard to the student's perceptions and practices of undertaking doctoral research. Confusion in these areas is a matter that directly affects the outcome of the dissertation as well as the PhD student's future research practices.
\end{abstract}

Keywords: Best practice; doctoral research; participative drawing method; PhD student; supervision.

\section{Background/Context}

I was lucky; I had an idea of what I wanted to research. Don't get me wrong; I knew I had a lot to learn about my topic and 
the process of doctoral research. Nevertheless, I recall being very enthusiastic and excited about the thought of all this learning before me. However, when I eventually started it was much harder than I thought. It seemed I was spending hours reading and yet making very little progress. There were good times and bad times, times when I felt scholarly and in control and times where I was ready to give up. My supervisor sessions were similarly good and bad. It seemed the doctoral research process came down to the repetitive act of rewriting sections. Moreover, it appeared the rationale for many of these edits correlated to her mood. On one occasion, she had me edit a section that she actually wrote! I didn't say anything - just changed it. By the time I was in the final phases of my PhD, I was sick of the study. I just wanted it finished. When I had completed and was waiting to receive my PhD, I was so happy, so pleased with myself, it's as if the delayed gratification created a sense of euphoria beyond expectation. It's a part of me now. Would I do it again? - no. Any regrets? Also no, but without it I would not be who I am today.

It would be fair to say that the act of undertaking doctoral research is somewhat daunting. It is also worth noting that doctoral research exists within a complex mix of aspirations and expectations. Doctoral students operate not on their own, but against the backdrop of pressures and agendas from family, supervisors, peers, and institutions. For this reason, insights into the research processes that doctoral students employ and their experiences of how they plan and achieve the various phases of work, would be beneficial to our understanding of what is required and how to prepare students to leverage the benefits of doctoral study. The purpose of this paper is not to debate whether there is a 'right' or 'wrong' way of undertaking doctoral research. Rather, the paper reports on the various approaches $\mathrm{PhD}$ students employ in their doctoral research. It is worth mentioning that this paper is derived from the first author's PhD study on "An investigation into the way $\mathrm{PhD}$ students utilise Information Communication and Technology (ICT) to support their doctoral research process" but the ICT aspect was eliminated from the data analysis for the purpose of this paper. Insights from this study will serve to inform as well as enhance, our understanding of the conceptions and practices of doctoral students in order to provide an opportunity for academics, especially supervisors of postgraduate research students, to provide better support for PhD students through their doctoral research process.

\section{Literature Review}

There is a general acceptance that doctoral research is a crucial process in the exercise of scholarship (Åkerlind, 2008; Brew, 2001; Council of Graduate Schools (CGS), 2005; Kiley \& Mullins, 2005; Meyer, Shanahan, \& Laugksch, 2005), that is so important in the development of an academic career (Hoskins \& Goldberg, 2005; Leonard, Becker, \& Coate, 2005). It is a process not only focused on 
developing the practice of research, but also the development of an identity within a particular field (Golde, 1998).

While some $\mathrm{PhD}$ students see doctoral research as a means to become an academic (Åkerlind, 2008), many regard the $\mathrm{PhD}$ as an essential qualification for a variety of career opportunities outside the university (Leonard et al., 2005). A study by Stubb, Pyhältö, and Lonka (2011) found 30\% of their doctoral student sample stated the purpose for gaining a PhD qualification was to improve their status and salary rather than a particular occupation. Wood (2006) also found PhD students frequently cited 'changing as a person' as a significant element of doctoral research. A study by Wellington (2012) found a variety of possible reasons why student undertook doctoral study, ranging from a future role in academia to personal development and achievement.

While the purposes for undertaking doctoral research may vary, the procedures associated with empirical research typically follow four core phases according to Gardner (2008): Preparation, Fieldwork, Analysis and Writing.

1. Preparation: when a doctoral student creates a research project proposal, reads relevant literature and constructs a research framework.

2. Fieldwork: when the doctoral student collects data as planned according to his or her research framework.

3. Analysis: when the doctoral student engages with the collected data, in alignment with the designed research framework and the existing literature.

4. Writing: when the doctoral student writes the thesis as a fulfilment of the degree requirements.

It appears that this structure is not, however, well known by PhD students. A study by Meyer, Shanahan, and Laugksch (2005) found that many PhD students conceptualise what 'research' is and how it should or should not be done, very differently to each other and their supervisors. For instance, they showed PhD students focused more on concrete activities such as information-gathering, discovering facts and uncovering gaps in the research rather than following the procedural framework of preparation, fieldwork, analysis and writing.

It is likely that instead of following core phases, doctoral students conceptualise their doctoral research process on the immediate scholarly environment in which they are situated (Gardner, 2007; Pyhältö, Stubb, \& Lonka, 2009; Stubb et al., 2011). In this way, students will look for and adopt views and practices they perceive to be useful (Sweitzer, 2009). In some cases, the dominant influence will be supervisors, but in others it is just as likely to be peers, either from within their department/discipline or outside of it (Kaplan \& Maehr, 1999; Seifert, 2004). Given that different disciplines reflect different conceptions of knowledge and learning (Golde, 2010), it seems reasonable to accept that doctoral students will believe that appropriate research practice in one discipline may well be inappropriate in another. 
In summary, doctoral research embodies processes and practices alien to most students and yet it is a process that demands a high level of student autonomy. At the same time, while there is increasing demand on supervisor accountability and performance, it is clear that the supervisor role must go beyond disciplinespecific models in teaching and defining the processes and procedures that underpin doctoral research. Against this and the backdrop of departmental expectations, doctoral students are responsible for forging clear ontological and epistemological views, coherent practices and conforming to expectations of research efficiency and productivity. Doctoral students' conceptions of doctoral research are likely to influence the quality of the work and the development of research process and practice (Pearson \& Brew, 2002). For these reasons, investigating the ways students plan and achieve the various phases of research work in their doctoral process is particularly germane in growing competitive landscape of academic research. Such investigations can help guide the development of frameworks aimed at enhancing the teaching and learning practices in the doctoral research process.

\section{Study Design and Methods}

In order to highlight doctoral student's practice and experience, the study adopted a case-based, biographical approach (Guba \& Lincoln, 1989) aimed at generating rich descriptions of the student's conceptions of doctoral research, the structural elements associated with processes and logistics and how these conceptions and practices are interlinked. A general interpretive approach was used to analyse the data. This provided a recognised framework and epistemological basis for exploring the meanings and purposes associated with each participant and their practice (Guba \& Lincoln, 1989, p. 106). Discussions with the participants encouraged us to 'see' through the lens of the participants, situating ourselves in their space, rather than placing ourselves apart or outside their experience. Employing a co-constructed, systemic, iterative approach served as a way to explore the topic while minimising the risk of incorporating unidentified bias through our assumptions. It was our hope that weaving together aspirations, conceptions and practices would have a transformative effect on both the student and the researcher (Nelson, 1994) through the awareness of different doctoral research processes and practices that exist.

Two data sources were generated: 1) Diagrams of Practice: study participants created drawings, in their own time, of their conceptions of doctoral research process; and 2) Discussions of Practice. Study participants discussed their illustrations, explaining them in detail. These sessions elicited data that enhanced the illustrations. The result was that the initial drawings become more detailed with the addition of terms, shapes, colours and connecting lines. These additions, in some cases, initiated considerable dialogue that at times, ventured beyond the research process and incorporated a variety of doctoral-related incidents. The 'explicitness' of the drawings, and each participant's 'point of view' (explanation) allowed us a view beyond what conventional approaches such as surveys or interviews are unable to offer (Spencer, 2011). 
Participants: Three questions were used for recruiting participants for this study. The questions were:

1. My discipline background is

a. Sciences

b. Health Sciences

c. Humanities

d. Commerce

2. What is your current research phase? Circle as many as it suits.

a. Preparation Phase

b. Fieldwork Phase

c. Analysis Phase

d. Writing Phase

3. Please indicate the ratio (within 10) of how much your workload is, according to the research phase that you have chosen in question two. For example, write 5:5 if you have a balanced workload between Analysis Phase and Write-up Phase.

Preparation Phase

Fieldwork Phase

Analysis Phase

Writing Phase

4. How do you rate your ability to use ICT?

a. Expert and skilful

b. Fairly skilful

c. Not at all skilled

d. Not applicable

Twenty full-time doctoral students volunteered for the study. From this group nine were selected based on their study type being 'empirical' (i.e., with fieldwork involved), a mix of $1^{\text {st, }} 2^{\text {nd }}$ and $3^{\text {rd }}$ year experience and their selfreported level of computer literacy as 'high'. The year of study was converted to study 'phases' defined as Early (approximately 1 year), Middle (approximately 2 years) and Final (approximately 3 years). 'Early' refers to a student who could be broadly described as in the preparation phase, while 'Final' refers to a student who is the final write-up phase in preparation for submission. 'Middle' refers to anyone who isn't 'Early' or 'Final'. As previously mentioned, Question 4 on the doctoral students' use of ICT was excluded in the data analysis for this paper.

Table 1 presents a summary of the distribution for the participants' discipline areas and their $\mathrm{PhD}$ phases as defined by this schema. 
Table 1: The PhD phases and the discipline backgrounds of the student participants

\begin{tabular}{c|c|c}
\hline PhD Phase & Participant No. & Discipline \\
\hline Early & 2 & Health Science \\
& 5 & Science \\
& 6 & Commerce \\
\hline Mid & 1 & Science \\
& 7 & Commerce \\
& 8 & Commerce \\
\hline Final & 3 & Humanities \\
& 4 & Humanities \\
& 9 & Health Science \\
\hline
\end{tabular}

\section{Data}

Participants were invited to create a drawing of the research process. They were allowed to use any form they wished: sketch, shapes, mind-maps, cartoon etc. The participants carried out the task in their own time, unsupervised by the researchers over a period of 5-7 days. Participants were free to include text, either on the drawing or as an accompaniment.

Once completed, participants met one of the researchers to discuss what they had generated. This allowed an opportunity for the participants to articulate what the diagrams represented, particularly:

- their perspectives about their doctoral research process;

- the drawing style used to illustrate their research practice;

- their emphasis on certain aspects of doctoral research.

During these meetings, participants were encouraged to talk freely and to make additions to the diagrams. These sessions played a key role in forming meaning from the drawings.

\section{Analysis and Discussion}

A general inductive approach (Guba \& Lincoln, 1989) was employed to guide the process of coding and analysing the audio recordings of the discussion sessions. Qualitative analysis software (NVivo) was employed to facilitate a systematic, iterative method of coding. The process of the analysis for participative drawing phase 1 is summarised in Figure 1. 


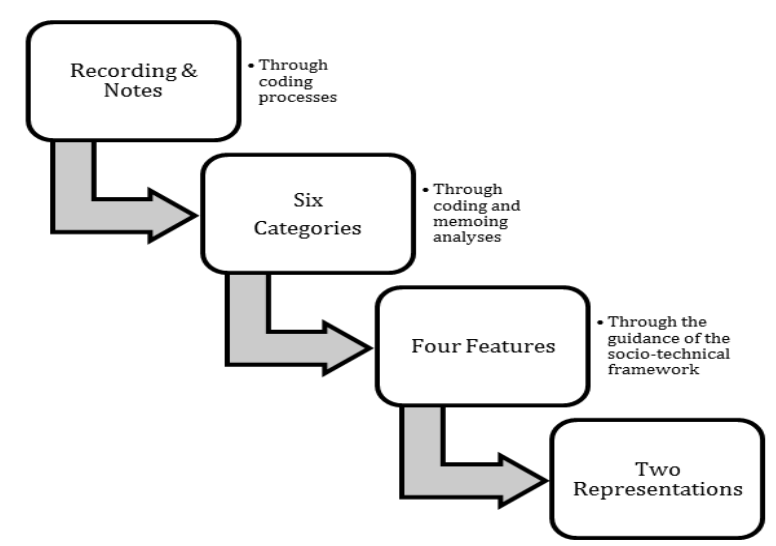

Figure 1: The analysis process for participative drawing Phase 1.

To gain an overall sense of the data, the analysis involved repeated reviews of the audio- recorded discussion sessions, researcher notes and the texts and markings on the participants' drawings, as shown in the example in Figure 2 below. This iterative process led to the identification of an initial code list based on each of the participants' personal explanations of their doctoral research process. As emphasised earlier, the ICT aspect as presented in all the following drawings would not be analysed and discussed in this paper.

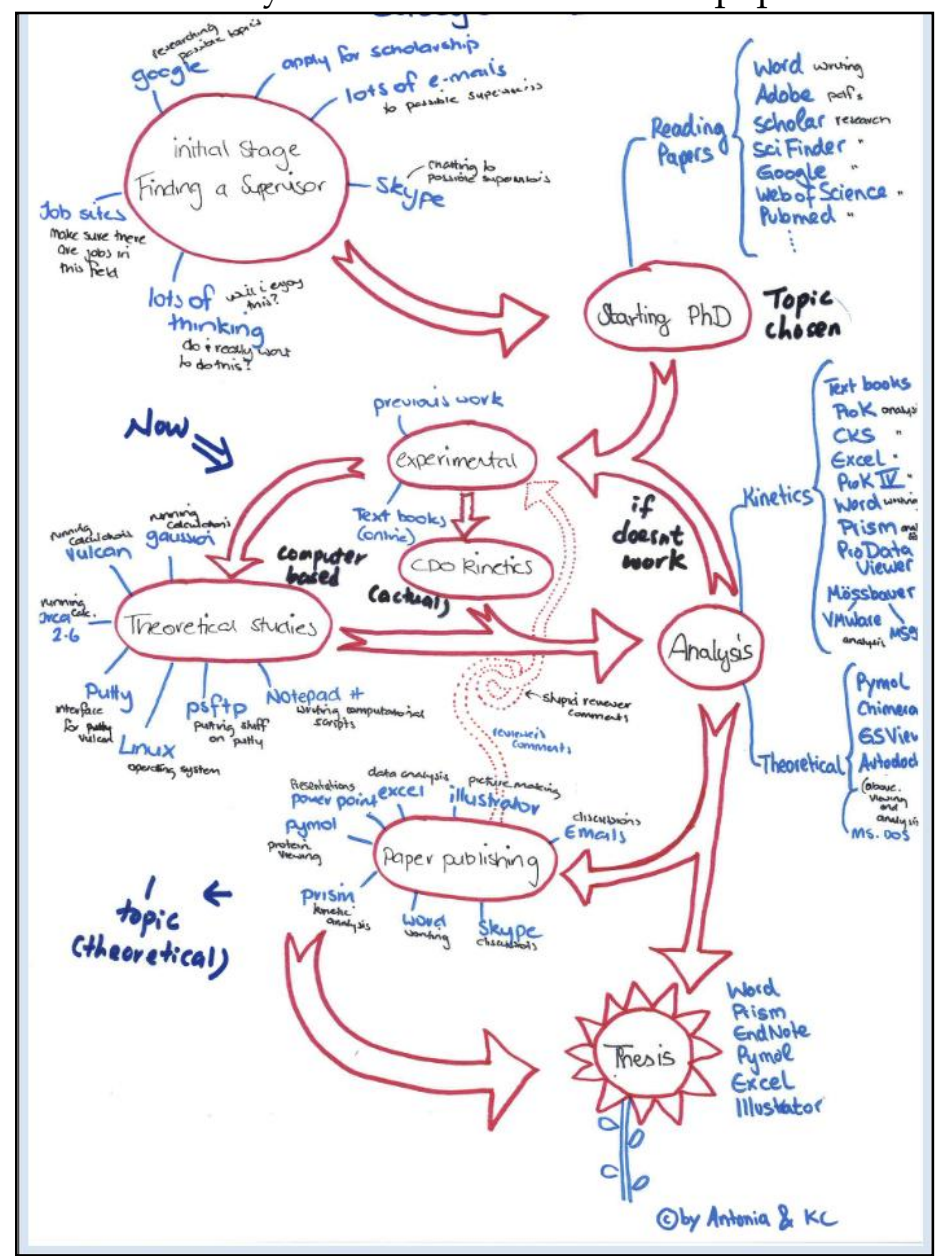

Figure 2: Participant drawings showing further markings in 'dark blue' \& 'black' that were added during a discussion session. 
As shown in Figure 2, the doctoral research process started by securing a supervisor before engaging in experimental processes by referring to theoretical studies and developing analysis in order to produce a thesis (note the words in red circles). The initial coding based on the individual participants' drawings (highlighter, thick lines, circles, numberings, etc. on each drawing) was examined repeatedly through discussion sessions until the students had no more to add. This process helped both parties gain clarity and enhance the trustworthiness and authenticity of the data. It also exemplifies how the research process can encourage participants to take on a "researcher-like" role and experience the invested outcome of the study (Green, Rafaeli, Bolger, Shrout, \& Reis, 2006). This process of gaining clarity by discussing and adding additional notes was undertaken in an informal relaxed manner. The diagrams offered an ideal platform for stimulating focused, meaningful discussion.

Categories were developed through the process of breaking down, separating, sorting, examining, comparing, and conceptualising the coded data. Every segment of the data was coded through the use of descriptive labelling. Relationships between these descriptive codes were then developed into categories through iterative processes of reworking and refinement. These processes gradually became more detailed and sophisticated with the involvement of both the researcher and the participants.

The Process: We found that the participants constructed their perceptions of the doctoral research process in three distinct ways: a) Linear vs. Non-Linear; b) Traditional vs. Non-Traditional; c) Simple vs. Complicated.

a) Linear vs. Non-Linear

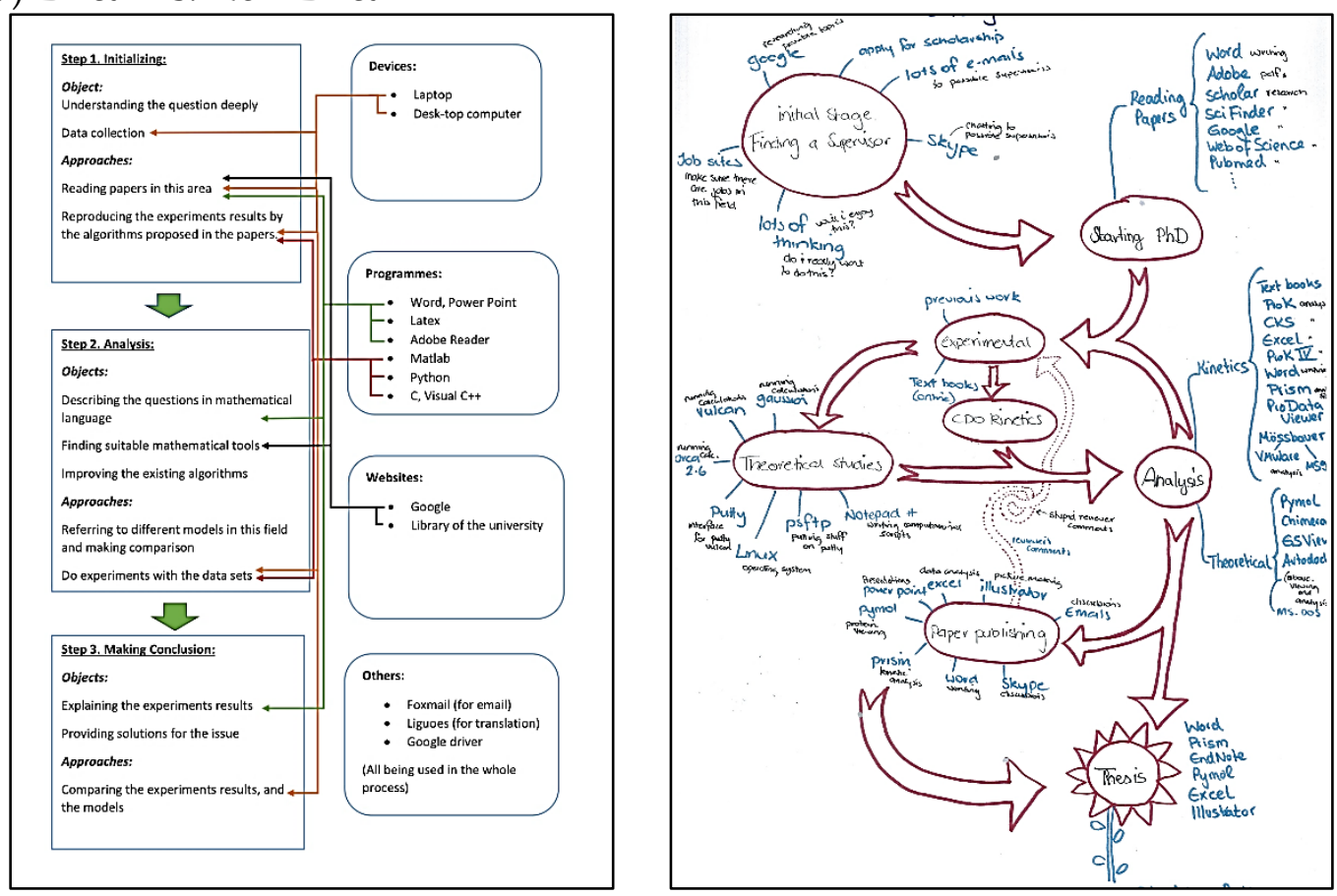

Figure 3: Participant drawings illustrating linear (on the left) and non-linear (on the right) representations of doctoral research process. 
Figure 3 shows two examples which serve to illustrate differences in the way these two students perceived the process. The image on the left illustrates doctoral research as a 'three step' sequential process, from generating the research topic to running analysis followed by making conclusions. The emphasis on the linear process is displayed by the student use of green directed arrows between the steps. Six participants represented their understanding of doctoral research in a similar linear way. The drawing on the right depicts a non-linear form. One of the three proponents of this non-linear approach explained doctoral research as never straightforward but a mix of moving forward, backward and sideways. In all three non-linear cases, these depictions showed a higher degree of 'messiness'.

The two participants in their early $\mathrm{PhD}$ phase and the mid-PhD phase mentioned how perplexing (messy) the doctoral research process was. This was repeatedly stated by these students in discussions and presented in their diagrams. It was, however, surprising to discover 'messiness' in the diagrams of participants in the final phase. The assumption was that these more experienced students would be in a position to articulate, retrospectively, the process in a clear methodical manner.

b) Traditional vs. Non-Traditional

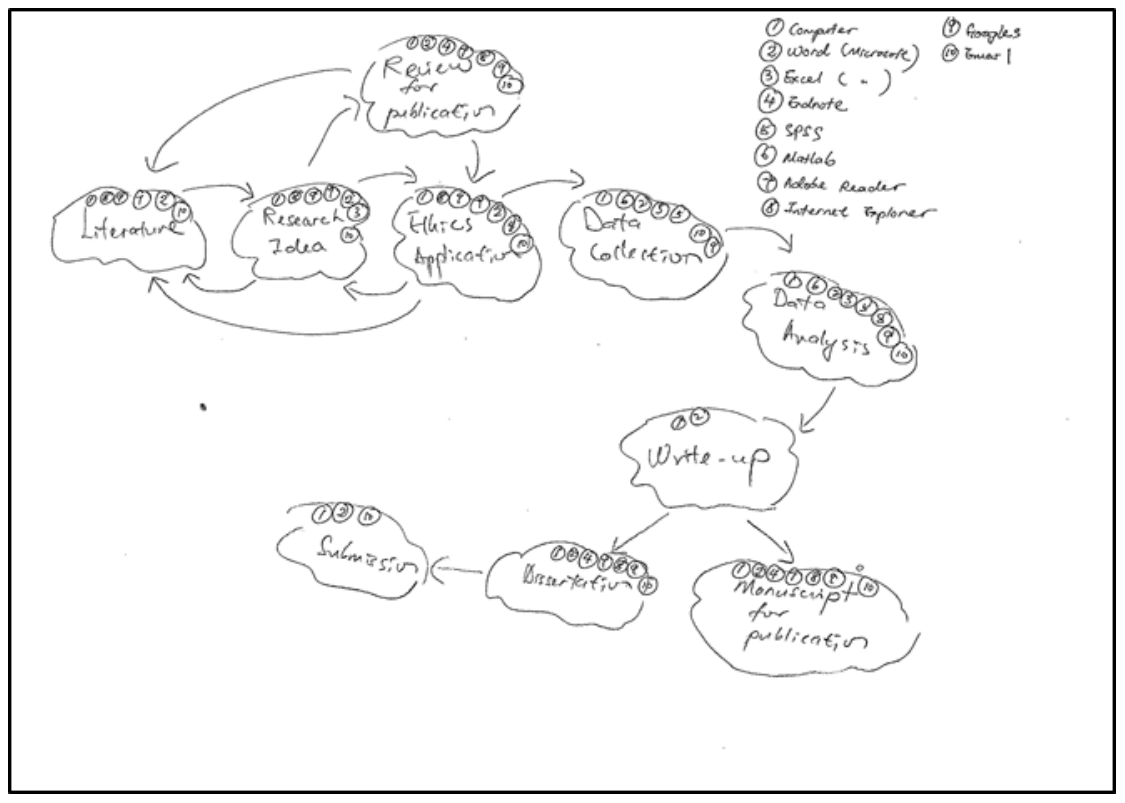




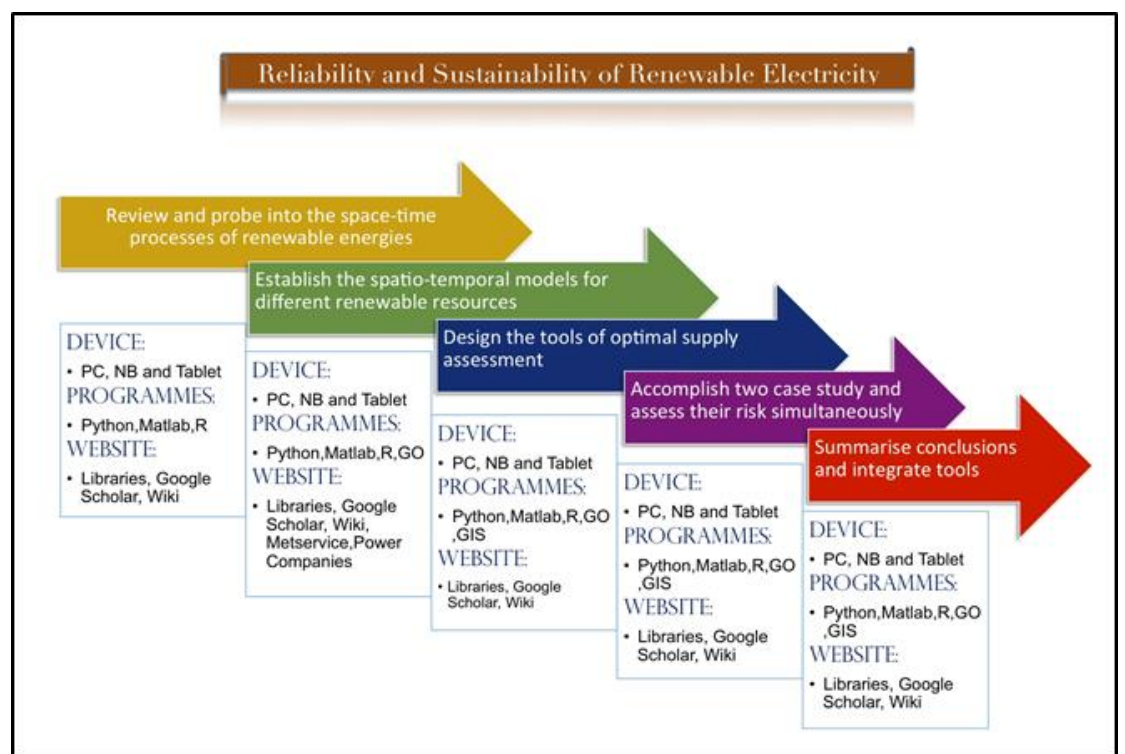

Figure 4: Participant drawings illustrating traditional (on the top) and non-traditional (at the bottom) representations of the doctoral research process.

Figure 4 shows two further depictions of the doctoral process, this time illustrating traditional and non-traditional approaches to doctoral research. The first image (on the top) shows a representation of the process illustrated in a 'traditional' format: from literature review to data collection and analysis followed by a write-up. The emphasis on the traditional process is displayed by the focus on finding a 'gap' in the literature that leads to the 'research idea' and 'data collection and analyses'. Six participants represented their doctoral research in this manner. The other three participants opted for a more nontraditional form which they felt showed 'innovation' in developing a personal approach to research practice.

While we expected that students in the early and mid-PhD phases would be conventional in their illustrations of process, two were not. In these cases, there was clearly an interest in doing something different.

c) Simple vs. Complicated

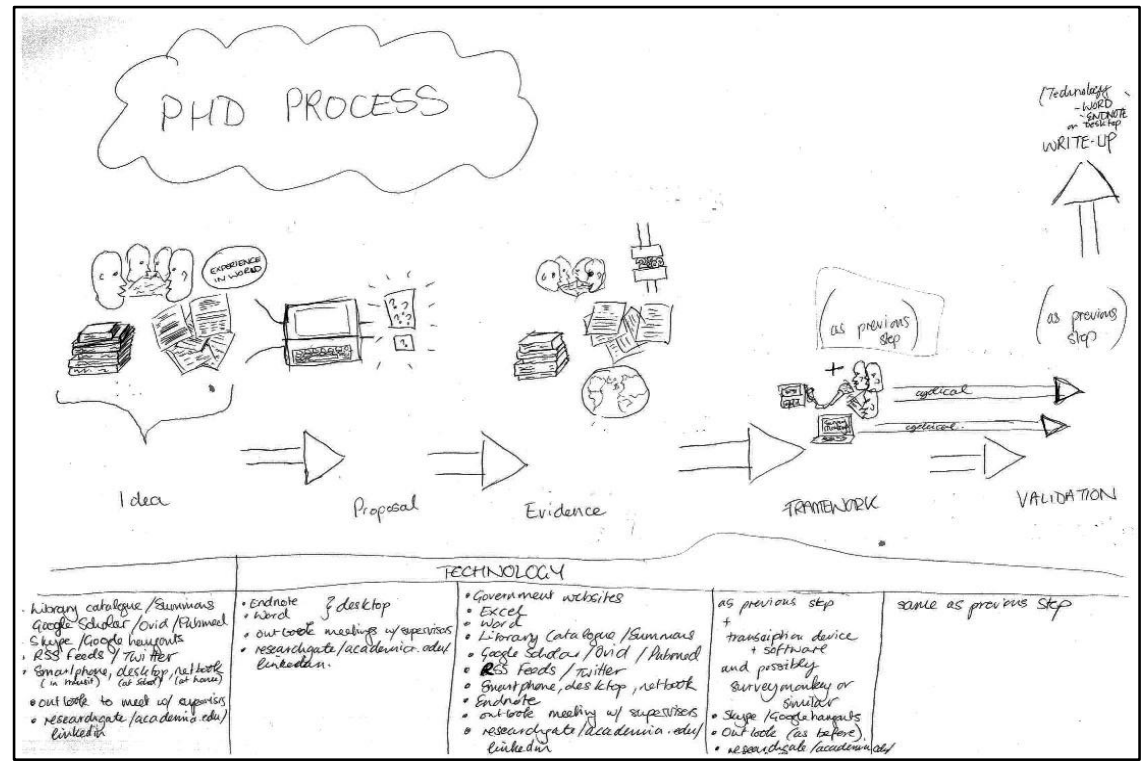

(C) 2017 The authors and IJLTER.ORG. All rights reserved. 


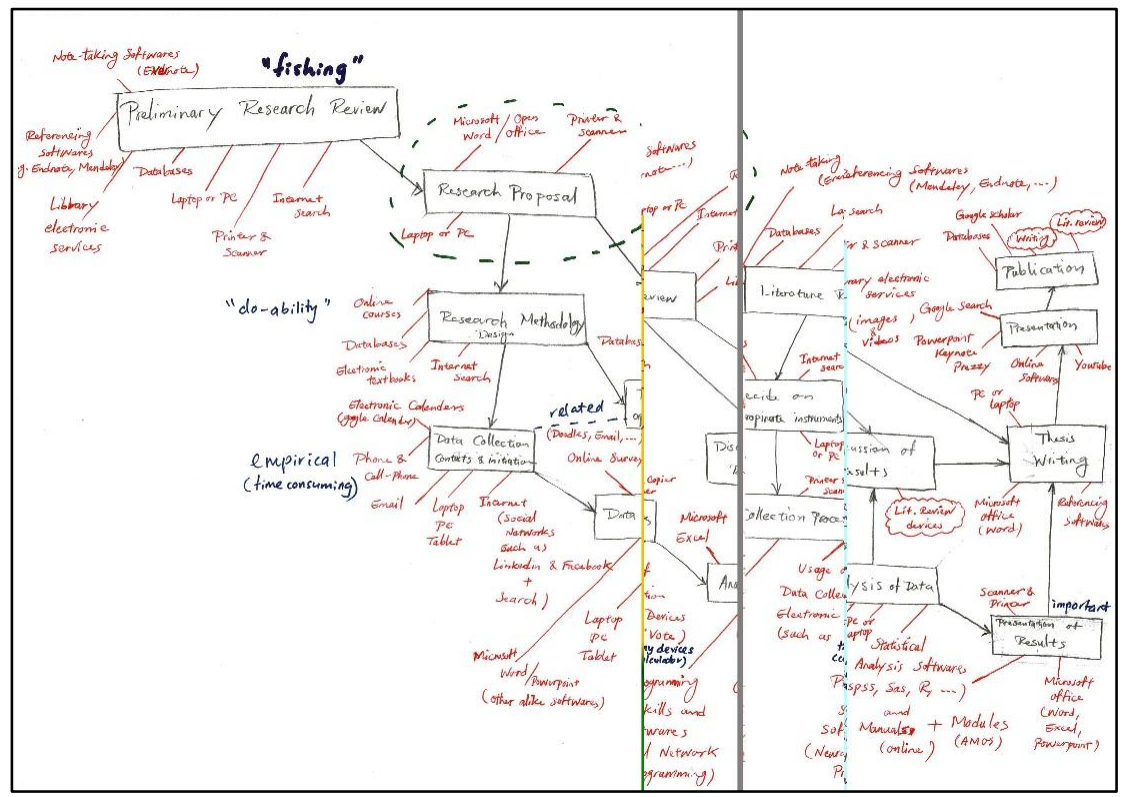

Figure 5: Participant drawings illustrating simple (on the top) and complicated (at the bottom) representations of the doctoral research process.

Similar to the illustration on Figure 5 (on the top), seven students represented their doctoral research in a simple layout that captured their idea of the project to proposal preparation, followed by collecting evidence, developing framework and generating validation ended by write-up. The emphasis on the simplicity is displayed by the focus on the 'lay terms' used in the drawing. Others, however, chose to present their doctoral research in a 'network' layout with linkages among the 'tasks-to-do'. In this way the diagram reveals linkages showing how particular stages affected important decisions relevant to other stages. It was interesting that the author of the diagram in Figure 5 (at the bottom) spoke of doctoral research as a rather 'tortuous' process where it was easy to get confused and lost.

Students in the early phase of their doctoral research tended to represent their processes in more complex ways, while those in the final phase of doctoral research presented in more 'simplistic' forms. We had expected the reverse. We thought it was likely that at start-up, PhD students would have a linear, textbook style view of the process that lacked insight into the complexities and those at the end of the process would be much more conscious of the complexities involved.

Finding-2 The Starting Point: All students talked a great deal about the 'starting point' of their doctoral research. Findings from the analysis of the drawings as well as the discussions showed that the participants began their doctoral research in three different ways: a) With an idea; b) 'Fishing' for an idea; c) Finding a supervisor as presented in Figure 6 below. 


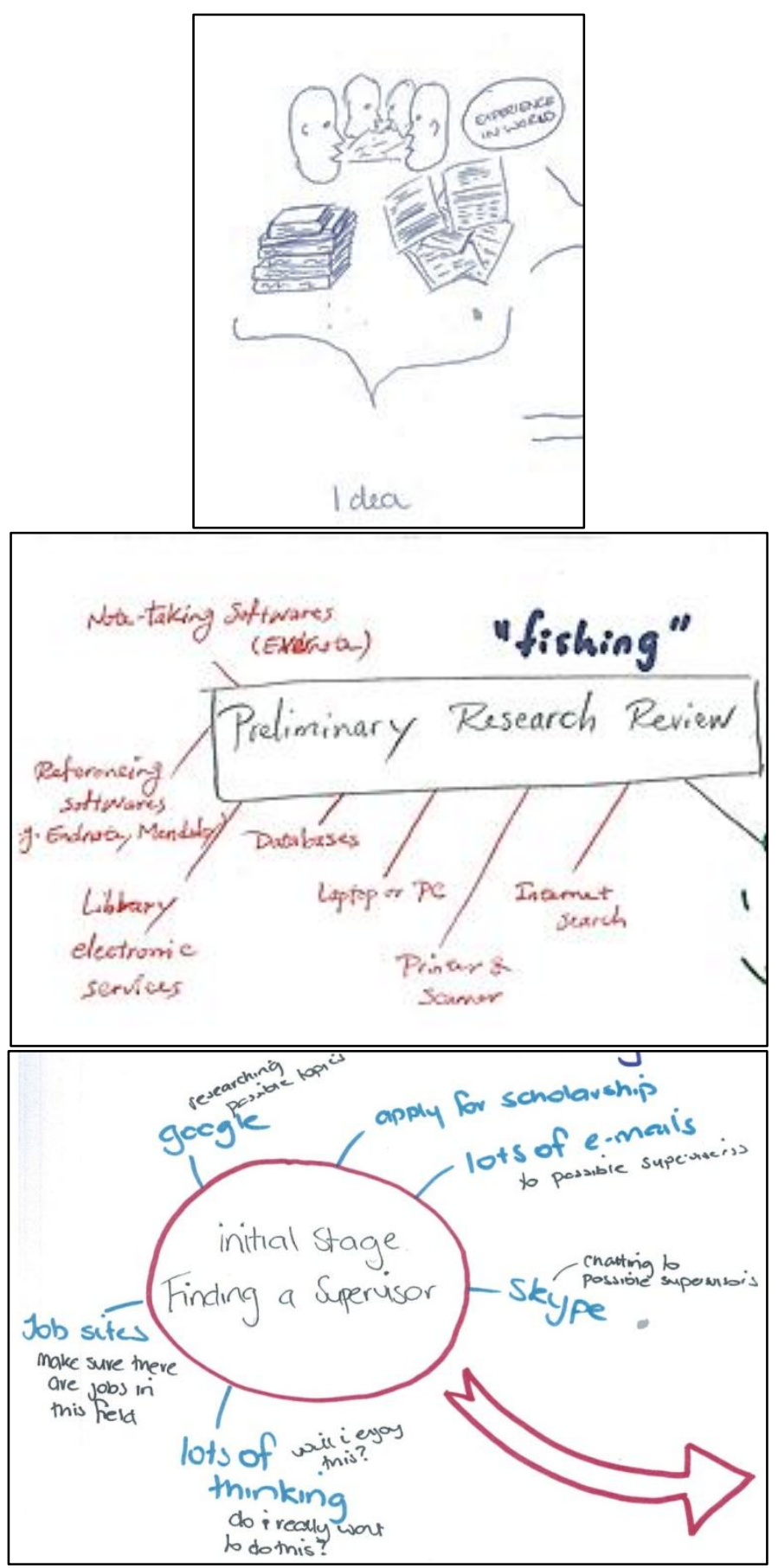

Figure 6: Participant drawing illustrating core elements perceived as important starting points of their doctoral research process.

All indicated a preference for, and dependence on, a way to begin their doctoral research. Three believed that one has to have a research idea in order to start the doctoral research process. A further three preferred to begin their doctoral research by finding a 'gap' in the literature in order to generate a research idea. The remaining three identified the need to secure a supervisor as the first and most important task. 
Finding-3 The Language Used: Findings from the analysis of the drawings as well as the discussion sessions showed that the participants were very dependent on language to mediate process and meaning within their diagrams. Typically, language was used in three different ways: a) General terms; b) Specific terms; c) Structural terms as presented in Figure 7 below.

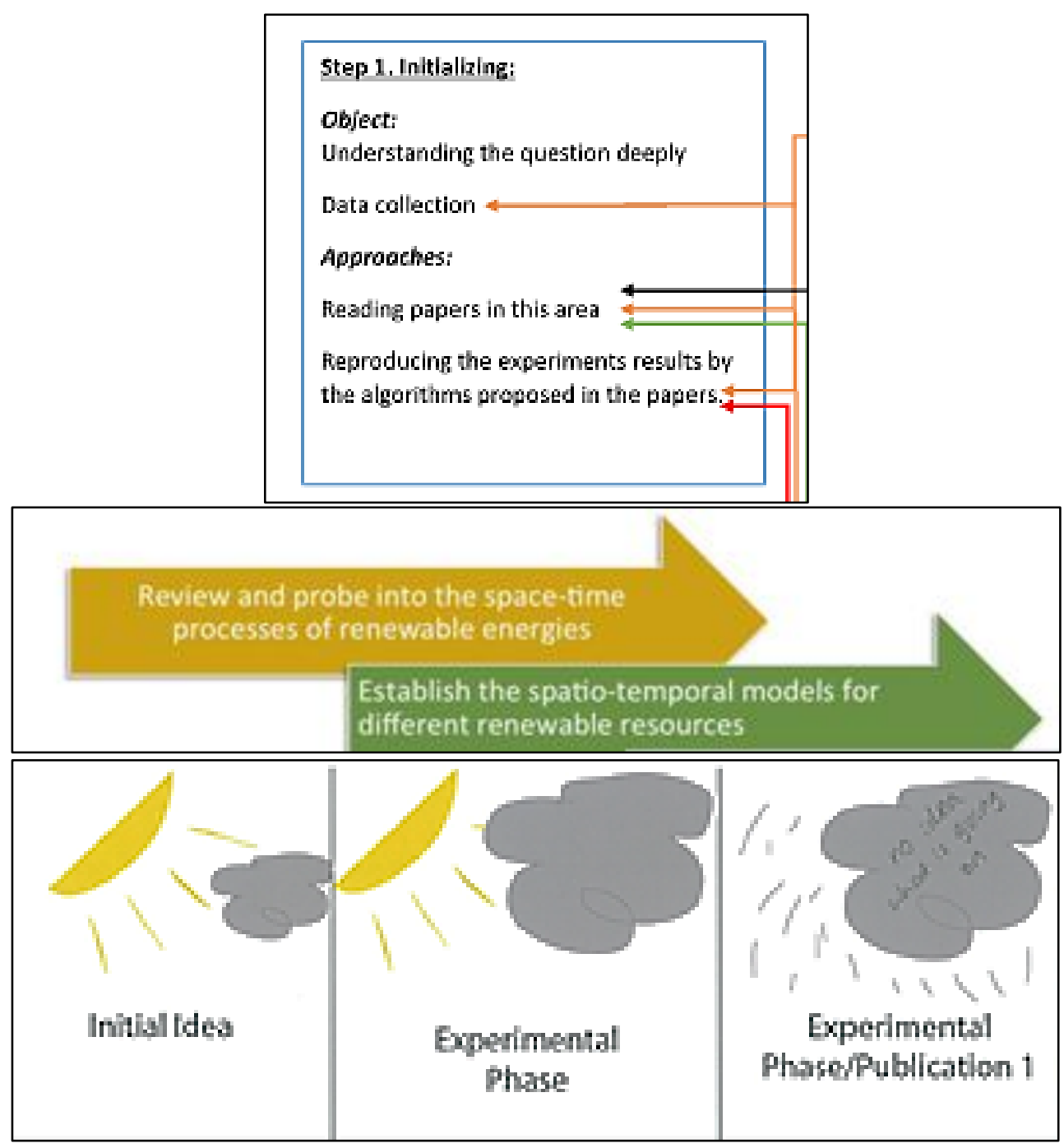

Figure 7: Participant drawings illustrating different languages used to describe the doctoral research process.

Four students used general terms to describe the processes in the light of completing a thesis, such as "Analysis", "Literature", "Research Proposal" and "Initialising" to describe the steps in their doctoral research. Others chose specific terms or phrases to illustrate each step in regards to the content of their thesis, such as "Use GIS to identify patterns in the recorded features for discussion in the body of the thesis" and "Establish the spatio-temporal models for different renewable resources" respectively. Three of the participants adopted structural terms to highlight their practices, such as "Validation", "Submission" and "Publication" in order to explain the process of their doctoral research. 
Finding-4 Participative Drawing vs. Questionnaire: This finding focuses on the methods used by the researchers to gather the data. Findings from the analysis of the questionnaire and the drawings showed the limitation of using questionnaire-only data.

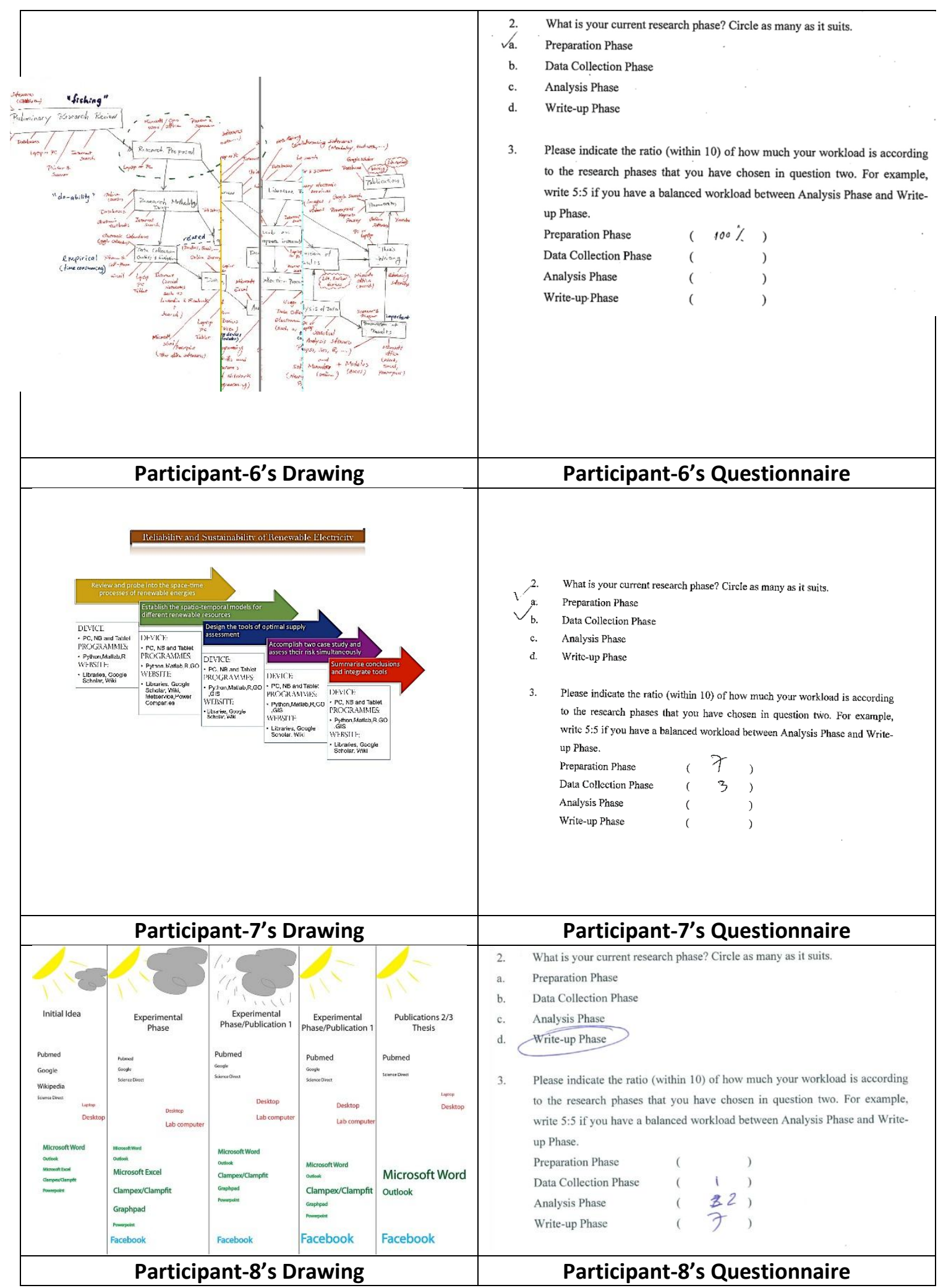




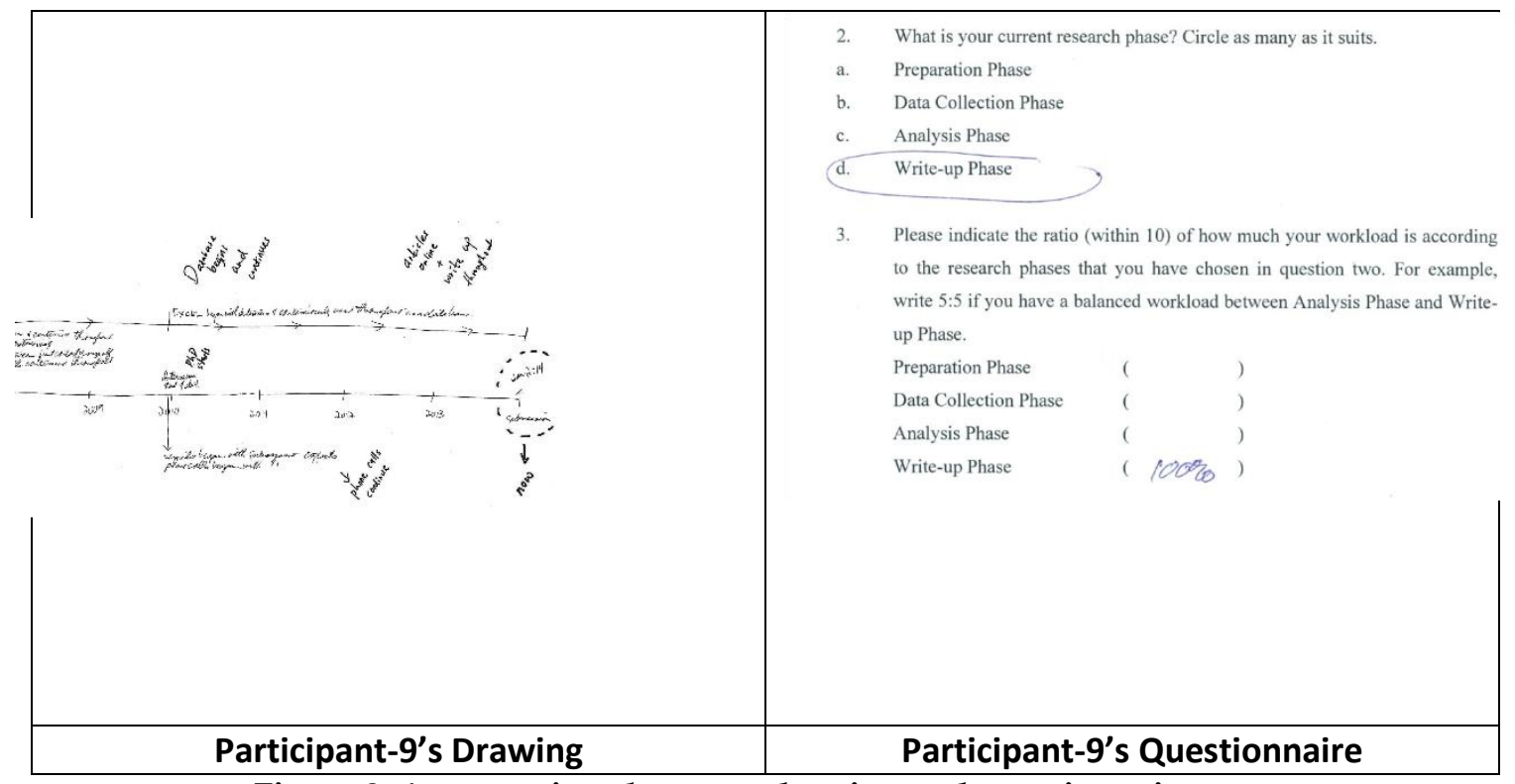

Figure 8: A comparison between drawing and questionnaire.

Findings from both the participants' questionnaire as well as drawings analysis indicated the problem of using only questionnaire data to express the student understanding of the process of carrying out doctoral research. As shown in Figure 8, the questionnaire data was not as rich or personal as the data presented in the drawings. Even with the discussion data, the individual student's process of undertaking doctoral research was less comprehensive and thorough. During the informal discussions, PhD students needed no prompting or persuasion to talk to their drawing; in fact, they were eager and engaged and spoke of the drawing task positively. In contrast, the questionnaire was not mentioned. It neither prompted discussion nor offered anything interesting or tangible to discuss. The drawings, on the other hand, offered cues and allowed students space to express a variety of aspects without the restrictions of the conventions of the written form or the researcher's presuppositions and therefore captured a higher degree of authorship and ownership - we felt it offered a more accurate reflection of the student's response to our inquiry.

In the discussion sessions, participants for the most part, focused on the outcome - gaining the $\mathrm{PhD}$ (product) rather than on how to gain the PhD (process).They explained that the outcome was more important than the process. In fact, it seemed that some had manipulated the process in order to speed up the completion time-frame. Many spoke about life post-PhD. For example, one participant pointed out that, "Basically you can't really get a job in Chemistry without a PhD". Another stated, "I need a PhD because I am a very academic person and I would like to stay in academia for the rest of my life".

In summary, for those just starting the doctoral research process, we had expected to see a degree of messy thinking and diagrams loaded with naïve complexity, but instead these participants tended to draw simple linear drawings. They possessed less knowledge than we were expecting and struggled with describing many of the phases and terms that define the various 
elements and interlocking relationships involved in the process. For those nearing completion we expected clarity in their thinking that would be represented in well-defined (symbolic) structured illustrations depicting their successful management of the 'chaos' or complexity of doctoral study. But instead we witnessed drawings that were extremely complex, confusing and illstructured. On reflection, it is not surprising that these students remained cognisant of the complexities, with a lack of iterative processes that are assumed and expected from our experiences at completion, in order to ensure sound alignment.

The importance placed on the 'starting' phase by participants was also unexpected. This appeared to be a point of concern for a number of participants. We were expecting students to recapitulate the research strategies and approaches developed during their Master Degrees. Instead, we found most of the students were very uncertain and naïve concerning their abilities to start research. The discussion sessions revealed that the students in the early phase knew very little about the processes to follow. Any anxiety during this early phase was not the result of navigating the chaos of tasks, but more about not knowing what tasks were relevant and what to do next.

On a more positive note, we were pleased that we included diagramming as a data capture technique. The students found the process useful and enjoyable. They created a level of infirmity that allowed for open and honest dialogue. At these sessions, students willingly added meaning and extended the accounts beyond what could be interpreted from the diagrams alone. It was also fascinating to see how language was used within the diagrams and orally to mediate meaning through a variety of forms and styles.

\section{Conclusion}

The purpose of this study was to investigate the ways $\mathrm{PhD}$ students conceptualised and practised doctoral research. The focus was on a group of PhD students' conceptions as well as their practices in different stages of doctoral research processes and thus, the study did not examine the broader domain of individuals or groups associated with the PhD process, such as the supervisors or peers. While on the surface, the small cohort appears to imply limitations to the research, it is important to note the research aimed to explore deep data of individual experiences as opposed to a broader more general approach.

The findings of this study have relevance for the broader tertiary population to engender awareness of different ways to understand research into student research practices. We hope it will provide an opportunity for academics, especially supervisors of postgraduate research students, to understand $\mathrm{PhD}$ students' research processes as well as practices and/or to what degree support might be required to support PhD students. It is hoped that these findings will help promote a deeper conversation about the ways PhD students understand the process and practice of doctoral research. Additionally, visual and situated behavioural data could be employed in higher education research as such data 
may offer new insights not found in data gathered through questionnaires and surveys. Perhaps research on larger and more diverse groups of students could be considered to obtain more representative data of the student population, as this study is focussed on a small group of students at one university.

The process and outcomes of this study have convinced us of the benefits of visual methodologies within higher education research. We hope this work acts as a catalyst for those looking for new ways of undertaking research, particular those involved in the field of doctoral research.

\section{Acknowledgement}

The study presented in the paper is derived from one aspect of KwongNui's $\mathrm{PhD}$ thesis on "An investigation into the way $\mathrm{PhD}$ students utilise ICT to support their doctoral research process", which was completed at the University of Otago, New Zealand in 2015 under the supervision of Sarah Stein, Russell Butson and Jacques van der Meer.

Retrieved from https://ourarchive.otago.ac.nz/handle/10523/6263

\section{References}

Åkerlind, G. (2008). A phenomenographic approach to developing academics' understanding of the nature of teaching and learning. Teaching in Higher Education, 13(6), 633-644. doi:10.1080/13562510802452350

Brew, A. (2001). Conceptions of research: A phenomenographic study. Studies in Higher Education, 26(3), 271-285.

Council of Graduate Schools (CGS). (2005). The doctor of philosophy degree: A policy statement. Washington, D.C.

Gardner, S. K. (2007). "T heard it through the grapevine": Doctoral student socialization in chemistry and history. Higher Education, 54, 123-140.

Gardner, S. K. (2008). "What's too much and what's too little?": The process of becoming an independent researcher in doctoral education. The Journal of Higher Education, 79(3), 326-350. doi:10.1353/jhe.0.0007

Golde, C. M. (1998). Beginning graduate school: Explaining first-year doctoral attrition. In M. S. Anderson (Ed.), New directions for higher education (pp. 55-64).

Golde, C. M. (2010). Entering different worlds. Socialization into disciplinary communities. In S. K. Gardner \& P. Mendoza (Eds.), On becoming a scholar. Socialization and development in doctoral education (pp. 79-95). Sterling, VA: Stylus: Sterling, VA: Stylus.

Green, A., S. , Rafaeli, E., Bolger, N., Shrout, P., E. , \& Reis, H., T. (2006). Paper or plastic? Data equivalence in paper and electronic diaries. Psychological Methods, 11(1), 87$105 . \quad$ Retrieved from http://docsfiles.com/pdf_paper_or_plastic_data_equivalence_in_paper_and_el ectronic_diaries.html doi:10.1037/1082-989X.11.1.87

Guba, E. G., \& Lincoln, Y. S. (1989). Fourth generation evaluation. Newbury Park, Ca: Sage.

Hoskins, C., \& Goldberg, A. (2005). Doctoral student persistence in counselor education programs: Student-program match. Counselor Education and Supervision, 44(3), $175-188$.

Kaplan, A., \& Maehr, M. L. (1999). Achievement goals and student well-being. Contemporary Educational Psychology, 24, 330-358. 
Kiley, M., \& Mullins, G. (2005). Supervisors' conceptions of research: What are they? Scandinavian Journal of Educational Research, 49(3), 245-262.

Leonard, D., Becker, R., \& Coate, K. (2005). To prove myself at the highest level: The benefits of doctoral study. Higher Education Research \& Development, 24(2), 135149.

Meyer, J. H. F., Shanahan, M. P., \& Laugksch, R. C. (2005). Students' conceptions of research I: A qualitative and quantitative analysis. Scandinavian Journal of Educational Research, 49, 225-244. doi:10.1080/00313830500109535

Nelson, A. (1994). Researching adult transformation as autobiography. International Journal of Lifelong Education, 13(5), 389-403

Pearson, M., \& Brew, A. (2002). Research training and supervision development. Studies in Higher Education, 27(2), 135-150

Pyhältö, K., Stubb, J., \& Lonka, K. (2009). Developing scholarly communities as learning environments for doctoral students. International Journal for Academic Development, 14(3), 221-232.

Seifert, T. (2004). Understanding student motivation. Educational Research 46(2), 137-149.

Spencer, S. (2011). Visual Research Methods in the Social Sciences (First ed.). London and New York: Routledge.

Stubb, J., Pyhältö, K., \& Lonka, K. (2011). Balancing between inspiration and exhaustion: PhD students' experienced socio-psychological well-being. Studies in Continuing Education, 33(1), 33-50.

Sweitzer, V. (2009). Towards a theory of doctoral student professional identity development: A developmental networks approach. The Journal of Higher Education, 80(1), 1-34.

Wellington, J. (2012). Searching for 'doctorateness'. Studies in Higher Education, 38(10), 1490-1503.

Wood, K. (2006). Changing as a person: the experience of learning to research in the social sciences. Higher Education Research and Development, 25(1), 53-66. 